CYSTIC FIBROSIS

\title{
Preferential reduction of quadriceps over respiratory muscle strength and bulk after lung transplantation for cystic fibrosis
}

\author{
C Pinet, P Scillia, M Cassart, M Lamotte, C Knoop, C Mélot, M Estenne
}

Thorax 2004;59:783-789. doi: 10.1136/thx.2004.021766

\begin{abstract}
See end of article for authors' affiliations

Correspondence to:

Dr M Estenne, Chest

Service, Erasme University

Hospital, 808 Route de Lennik, B-1070 Brussels, Belgium; mestenne@ulb. ac.be
\end{abstract}

Received 20 January 2004 Accepted 29 May 2004

\begin{abstract}
Background: In the absence of complications, recipients of lung transplants for cystic fibrosis have normal pulmonary function but the impact of the procedure on the strength and bulk of respiratory and limb muscles has not been studied.

Methods: Twelve stable patients who had undergone lung transplantation for cystic fibrosis 48 months earlier (range 8-95) and 12 normal subjects matched for age, height, and sex were studied. The following parameters were measured: standard lung function, peak oxygen uptake by cycle ergometry, diaphragm surface area by computed tomographic (CT) scanning, diaphragm and abdominal muscle thickness by ultrasonography, twitch transdiaphragmatic and gastric pressures, quadriceps isokinetic strength, and quadriceps cross section by CT scanning, and lean body mass. Diaphragm mass was computed from diaphragm surface area and thickness.

Results: Twitch transdiaphragmatic and gastric pressures, diaphragm mass, and abdominal muscle thickness were similar in the two groups but quadriceps strength and cross section were decreased by nearly $30 \%$ in the patients. Patients had preserved quadriceps strength per unit cross section but reduced quadriceps cross section per unit lean body mass. The cumulative dose of corticosteroids was an independent predictor of quadriceps atrophy. Peak oxygen uptake showed positive correlations with quadriceps strength and cross section in the two groups, but peak oxygen uptake per unit quadriceps strength or cross section was reduced in the patient group.

Conclusions: The diaphragm and abdominal muscles have preserved strength and bulk in patients transplanted for cystic fibrosis but the quadriceps is weak due to muscle atrophy. This atrophy is caused in part by corticosteroid therapy and correlates with the reduction in exercise capacity.
\end{abstract}

$\mathrm{T}$ he registry of the International Society for Heart and Lung Transplantation indicates that cystic fibrosis (CF) accounts for about one third of all bilateral lung transplantations performed worldwide ${ }^{1}$ and, over the last decade, this treatment has become a viable option for the management of many patients with advanced disease. In the absence of complications, transplantation results in dramatic improvements in overall clinical status, health related quality of life, and exercise tolerance. ${ }^{23}$

Static and dynamic lung volumes in patients transplanted for CF have been described in detail elsewhere, ${ }^{4}$ but only one study has assessed the function of respiratory and limb muscles. ${ }^{5}$ In this study, maximal static inspiratory and expiratory mouth pressures were reported to be normal and quadriceps strength was reported to be decreased in the seven patients studied, but interpretation of these results was made difficult by the absence of control values. In addition, the strength of individual muscle groups (such as the diaphragm and abdominal muscles) was not assessed specifically, and no measurement of muscle bulk was provided.

Better understanding of the cause of muscle weakness is needed to optimise post-transplant rehabilitation strategies. For instance, it would be useful to know if muscle weakness is primarily due to a loss in muscle mass or if dysfunction at the level of the contractile apparatus is present; both mechanisms have been incriminated in the skeletal muscle dysfunction of CF. ${ }^{6-8}$ A myopathy (associated with atrophy) has also been described in the limb muscles of patients with chronic diseases such as chronic heart failure ${ }^{9}$ and chronic obstructive pulmonary disease (COPD). ${ }^{10}{ }^{11}$ The myopathic process may involve the respiratory muscles, ${ }^{10}$ and may be associated with exposure to a low dose of corticosteroids. ${ }^{10} 11$ This observation may be particularly relevant to lung transplant recipients who are treated with corticosteroids throughout the postoperative period.

We have tested the hypotheses that, in patients transplanted for CF, (1) there is a reduction in the strength and bulk of respiratory and/or quadriceps muscles which is caused, at least in part, by corticosteroid treatment; and (2) quadriceps weakness and wasting contribute to limit exercise performance. We therefore assessed the following factors in 12 stable patients who had been transplanted for CF and 12 age, sex, and height matched normal subjects:

- the function and bulk of the diaphragm, abdominal muscles, and quadriceps;

- the relationship between muscle strength and bulk and immunosuppressive treatment; and

- the relationship between muscle strength and bulk and exercise capacity.

\section{METHODS}

Subjects

Patients who had undergone heart-lung (HLT) or bilateral lung (BLT) transplantation for CF at our institution were included in this study if (1) they had not incurred phrenic nerve damage during surgery; (2) their clinical state had been

Abbreviations: $B M I$, body mass index; $C F$, cystic fibrosis; FBM, fat body mass; FRC, functional residual capacity; $F E V_{1}$, forced expiratory volume in 1 second; LBM, lean body mass; Mdi, diaphragm mass; Pdi, trandiaphragmatic pressure elicited by twitch stimulation of the phrenic nerves; Pga, change in gastric pressure elicited by abdominal stimulation; PT, peak torque of quadriceps muscle; TLC, total lung capacity; VC, vital capacity. 
stable for the last 3 months before the study; (3) they were free of any decrease in forced expiratory volume in 1 second $\left(\mathrm{FEV}_{1}\right)$ suggesting the presence of chronic allograft dysfunction; ${ }^{12}$ and (4) they agreed to participate. At the start of the study in January 2002, 27 of the 52 patients with CF who had received a lung transplant at our institution since 1988 were alive. Of these 27 patients, 15 were excluded due to the presence of chronic rejection $(n=5)$, medical complications $(n=2)$, diaphragm paralysis $(n=1)$, and unwillingness to participate $(n=7)$, leaving 12 patients for study (five with HLT and seven with BLT). All patients but one were studied after the first postoperative year; the median time interval between transplantation and study was 47.5 months (range 8-95). At the time of the study the patients were taking a standard immunosuppressive regimen including cyclosporin $(n=5)$ or tacrolimus $(n=7)$, azathioprine $(n=8)$ or mycophenolate mofetyl $(n=1)$, and methylprednisolone $(n=12)$. Of the seven patients who were taking tacrolimus, five had been previously treated with cyclosporin for periods ranging from 22 days to 37 months.

The control group consisted of 12 normal subjects matched for age, height, and sex (table 1). These subjects, of whom 10 had participated in our previous study, ${ }^{13}$ were recruited from hospital personnel; they were all non-smokers and were free of any respiratory or neuromuscular disease.

All subjects were informed of the nature and extent of the study and gave written informed consent, as approved by the Human Studies Committee of the institution.

\section{Pulmonary function}

Measurements of standard pulmonary function were obtained by body plethysmography following the guidelines of the American Thoracic Society. ${ }^{14}$ Predicted values were computed using equations published by Quanjer et al. ${ }^{15}$ The patients performed an incrementally progressive, symptom limited, cardiopulmonary exercise test on an electrically braked cycle ergometer using standard techniques. After 5 minutes of adaptation to the mouthpiece the workload was increased by $10 \mathrm{~W}$ steps every minute to the point of exhaustion. The predicted value for peak oxygen uptake was derived from equations including sex, age, height, and weight. ${ }^{16}$

\section{Diaphragm mass}

Diaphragm mass was computed from values of diaphragm surface area and thickness. Diaphragm surface area was measured using a previously described technique based on spiral computed tomographic (CT) scanning. ${ }^{17}{ }^{18}$ The CT scanner (Somatom Volume Zoom, Siemens, AG, Erlangen, Germany) was also used to measure supine functional residual capacity (FRC). ${ }^{18}$ Diaphragm thickness was measured in the zone of apposition of the diaphragm to the lower rib cage by B-mode ultrasound using an $8-12 \mathrm{MHz}$ linear probe (Toshiba Power Vision 8000, Japan), as previously described. ${ }^{19}$ In all subjects, measurements of diaphragm surface area and thickness were obtained during voluntary relaxation at FRC in the supine posture. The mean of three measurements of thickness was used for analysis.

\section{Diaphragm strength}

With the subject lying supine the two phrenic nerves were maximally stimulated transcutaneously in the neck at a frequency of $0.5 \mathrm{~Hz}$ with $0.2 \mathrm{~ms}$ square wave pulses delivered from two electrical stimulators (Medelec, Surrey, UK). The resulting twitch transdiaphragmatic pressure was measured using conventional balloon tipped catheters placed in the oesophagus and the stomach, as described elsewhere; ${ }^{20}$ the oesophageal and gastric balloons were filled with 0.5 and $1.0 \mathrm{ml}$ of air, respectively. Subjects were instructed to breathe quietly for 20 minutes before stimulation to avoid twitch potentiation. Five runs of 5-6 twitches separated by 2-3 min of quiet breathing were obtained during voluntary relaxation against a closed airway at FRC; the last 2-3 runs were obtained during supramaximal stimulation. Twitches were considered valid and supramaximal based on standard criteria. ${ }^{21}$ The mean of the three twitches showing the largest transdiaphragmatic pressure was used for analysis.

\section{Abdominal muscle thickness}

The thickness of the rectus abdominis, external oblique, internal oblique, and transversus abdominis muscles was measured with a high resolution 8-12 Mhz ultrasound linear probe. Measurements were obtained on the right side with the subject relaxing at FRC in the supine posture, as previously described. ${ }^{22}$ Measurements were made in triplicate and the mean value was used for analysis. Abdominal muscle thickness was computed as the cumulative thickness of all four abdominal muscle layers.

\begin{abstract}
Abdominal muscle strength
With the subject in the seated position, bending the trunk slightly forward and resting the forearms on the thighs, paired bilateral stimulations of the lower thoracic nerve roots were delivered with a $90 \mathrm{~mm}$ diameter magnetic coil applied over the T10 spinal level and powered by two linked Magstim 250 stimulators (Magstim Co, Whitland, Dyfed, UK). ${ }^{22}$ The linking circuit was capable of precisely controlling the interstimulus interval. This interval was set at $33 \mathrm{~ms}$ and at least five measurements were performed at $100 \%$ maximal stimulator output. All stimulations were applied during voluntary relaxation against a closed airway at FRC. Changes in gastric pressure elicited by the stimulation were
\end{abstract}

Table 1 Mean (SD) characteristics of study population

\begin{tabular}{|c|c|c|c|c|}
\hline & $\begin{array}{l}\text { CF patients } \\
(n=12)\end{array}$ & $\begin{array}{l}\text { Controls } \\
\text { (n=12) }\end{array}$ & $\begin{array}{l}\text { Mean }(95 \% \mathrm{Cl}) \\
\text { difference* }\end{array}$ & $\mathrm{p}$ value \\
\hline Age (years) & $33.8(8.6)$ & $32.8(6.6)$ & $1.1(-5.7$ to 7.9$)$ & NS \\
\hline Sex & $8 \mathrm{M} / 4 \mathrm{~F}$ & $8 \mathrm{M} / 4 \mathrm{~F}$ & - & NS \\
\hline Height $(\mathrm{cm})$ & $1.68(0.07)$ & $1.70(0.09)$ & $-0.02(-0.1$ to 0.05$)$ & NS \\
\hline Weight (kg) & $53.6(8.5)$ & $61.3(12.2)$ & $-7.7(-17$ to 1.6$)$ & NS \\
\hline $\mathrm{BMI}\left(\mathrm{kg} / \mathrm{m}^{2}\right)$ & $19.0(1.8)$ & $21.1(3.1)$ & $-2.1(-4.3$ to 0.1$)$ & NS \\
\hline LBM (kg) & $44.0(8.5)$ & $50.8(11.0)$ & $-6.8(-15.5$ to 1.8$)$ & NS \\
\hline FBM (kg) & $9.7(3.6)$ & $10.6(2.6)$ & $-0.9(-3.7$ to 1.9$)$ & NS \\
\hline TLC (\% pred) & $100(9)$ & $103(10)$ & $-3(-12$ to 6$)$ & NS \\
\hline FRC (\% pred) & $114(20)$ & $108(22)$ & $6(-13$ to 25$)$ & NS \\
\hline $\mathrm{FEV}_{1}(\%$ pred) & $97(14)$ & $101(10)$ & $-4(-15$ to 7$)$ & NS \\
\hline VC (\% pred) & $94(12)$ & $103(10)$ & $-9(-19$ to 1$)$ & NS \\
\hline
\end{tabular}

CF, cystic fibrosis; BMI, body mass index; LBM, lean body mass; FBM, fat body mass; TLC, total lung capacity; FRC, functional residual capacity; FEV 1 , forced expiratory volume in 1 second; VC, vital capacity.

${ }^{*}$ Mean difference (with 95\% confidence intervals) between CF and control groups. 
measured and the mean of the three largest values was used for analysis.

\section{Quadriceps cross sectional area}

The cross sectional area of the quadriceps of the dominant leg was measured on a CT scan obtained midway between the femoral head and the medial femoral condyle. ${ }^{11}$

\section{Quadriceps strength}

The maximum isokinetic $(60 \%)$ strength of the quadriceps of the dominant leg was measured using a Cybex dynamometer.

\section{Nutritional status}

Nutritional status was assessed by computing body mass index, and by measuring lean and fat body mass using electrical bioimpedance (BIA, 101/S bioelectrical analyser, Akem, Florence, Italy). ${ }^{23}$

\section{Data analysis}

The muscular surface area of the diaphragm (Amu) was calculated as Adi $\times 0.84$ (where Adi is the total surface area of the muscle), based on the study by Arora and Rochester ${ }^{24}$ which showed that the surface area of the central tendon corresponds to $16 \%$ of total diaphragm surface area. Diaphragm mass was computed as Amu $\times$ Tdi $\times 1.04$, where Tdi is diaphragm thickness and 1.04 is the density of the muscle. ${ }^{24}$

Data are expressed as mean (SD) values or $95 \%$ confidence intervals (CI). Statistical analyses were made using paired and unpaired $t$ tests, single linear regression analysis, and covariance analysis; the latter was used to test whether the vertical distance between the regression lines obtained in the two groups was significant. In addition, a multiple linear regression analysis was performed to investigate the interpatient variability in the bulk and strength of the respiratory and quadriceps muscles. The following independent variables were included in the analysis: age, sex, body mass index, lean body mass, time between transplantation and study, type of transplant, presence of insulin dependent diabetes mellitus, mean daily dose of methylprednisolone received during the year preceding the study, and cumulative dose of methylprednisolone (calculated as the sum of all intravenous and oral doses received between surgery and study). The stepwise regression selection procedure was used to obtain the best model with the minimal number of predictors. Adjusted $R^{2}$ rather than $R^{2}$ values are reported to take into account the different numbers of predictors included in the models. A p value of $<0.05$ was considered statistically significant.

\section{RESULTS}

Mean anthropometric values and lung volumes in the patients and control subjects are shown in table l. The two groups were matched for age, sex and height; weight, body mass index, fat body mass, and lean body mass tended to be smaller in the patients, but the differences did not reach statistical significance. Seven patients had insulin dependent diabetes mellitus. Mean values for pulmonary function tests in the patients were within normal limits; in particular, FRC was similar in the patients and the normal subjects, both in the seated and supine positions.

The mean values for the bulk and strength of the diaphragm, abdominal, and quadriceps muscles are shown in table 2 and fig 1. Because of intolerance to oesophageal and gastric balloons, values of transdiaphragmatic and gastric pressure were not available in one patient; one control subject and one patient did not perform the exercise test. The mean twitch transdiaphragmatic pressure and diaphragm mass were similar in the patients and the normal subjects. In contrast, diaphragm mass normalised by lean body mass was $47 \%$ greater in patients than in controls $(p=0.002)$. Changes in gastric pressure elicited by abdominal muscle contraction were similar in the two groups. The cumulative thickness of the four abdominal muscle layers tended to be smaller in the patients than in the control subjects $(p=0.02)$, but this difference was exclusively caused by a reduction in the thickness of the external oblique and rectus abdominis muscles $(p<0.02$ and $p=0.005$, respectively). The transversus abdominis and internal oblique muscles had a similar thickness in the two groups.

Quadriceps peak torque and cross sectional area were 33\% $(\mathrm{p}=0.006)$ and $31 \%(\mathrm{p}=0.001)$ lower in patients than in controls. Plots of peak torque versus cross sectional area showed positive correlations in both patients $\left(r^{2}=0.77\right.$, $\mathrm{p}<0.001)$ and controls $\left(r^{2}=0.75, \mathrm{p}<0.001\right)$. Figure 2A shows that the relationships in the two groups were superimposed, indicating that quadriceps strength per unit cross sectional area was well preserved in the patients. On the other hand, mean values of cross sectional area per unit lean body mass were decreased by $20 \%$ in patients compared with controls ( $p=0.001$; fig 1 , lower right panel). Plots of quadriceps cross sectional area versus lean body mass (fig $2 \mathrm{~B}$ ) showed significant correlations in the two groups $\left(r^{2}=0.86, \mathrm{p}<0.001\right.$ in controls and $r^{2}=0.42, \mathrm{p}<0.02$ in patients), but the regression line computed in the patients was displaced towards lower values of muscle cross section $(\mathrm{p}=0.002$ by covariance analysis).

On average, peak oxygen uptake amounted to $56 \%$ of predicted (47-65\%) and was not significantly different between patients receiving cyclosporin and those treated with tacrolimus. The reduced peak oxygen uptake was due to a reduced exercise time and power output, but the patients did not reach their maximal ventilation; on average, the ratio of minute ventilation at peak exercise over maximum voluntary ventilation amounted to $46 \%$ (37-55\%). Nine patients stopped exercise

Table 2 Mean (SD) strength and bulk of respiratory and quadriceps muscles in the study population

\begin{tabular}{lllll}
\hline & CF patients & Controls & $\begin{array}{l}\text { Mean }(95 \% \mathrm{Cl}) \\
\text { difference* }\end{array}$ & P value \\
\hline Pdi $\left(\mathrm{cm} \mathrm{H} \mathrm{H}_{2} \mathrm{O}\right)$ & $24.3(4.5)$ & $27.0(7.1)$ & $-2.6(-8.1$ to 2.9$)$ & $\mathrm{NS}$ \\
$\mathrm{Mdi}(\mathrm{g})$ & $183(53)$ & $148(46)$ & $35(-10$ to 79$)$ & $\mathrm{NS}$ \\
$\mathrm{Mdi} / \mathrm{LBM}(\mathrm{g} / \mathrm{kg})$ & $4.22(1.22)$ & $2.87(0.49)$ & $1.34(0.52$ to 2.16$)$ & 0.002 \\
$\mathrm{Pga}(\mathrm{cm} \mathrm{H} \mathrm{O})$ & $91.1(28.8)$ & $92.2(27.5)$ & $-1.13(-26.7$ to 24.4$)$ & $\mathrm{NS}$ \\
$\mathrm{Tab}(\mathrm{mm})$ & $21.3(4.7)$ & $26.5(5.8)$ & $-5.3(-9.9$ to -0.6$)$ & 0.02 \\
$\mathrm{Tab} / \mathrm{LBM}(\mathrm{mm} / \mathrm{kg})$ & $0.49(0.09)$ & $0.52(0.06)$ & $-0.04(-0.1$ to 0.03$)$ & $\mathrm{NS}$ \\
$\mathrm{PT}(\mathrm{Nm})$ & $103.6(33.4)$ & $154.4(47.0)$ & $-50.8(-86.9$ to -14.8$)$ & 0.006 \\
quadCSA $\left(\mathrm{cm}^{2}\right)$ & $48.5(13.8)$ & $70.5(15.7)$ & $-22.0(-35.1$ to -9.0$)$ & 0.001 \\
quadCSA $/ \mathrm{LBM}\left(\mathrm{cm}^{2} / \mathrm{kg}\right)$ & $1.10(0.26)$ & $1.39(0.10)$ & $-0.29(-0.46$ to -0.12$)$ & 0.001 \\
\hline
\end{tabular}

Pdi, trandiaphragmatic pressure elicited by twitch stimulation of the phrenic nerves; Mdi, diaphragm mass; LBM, lean body mass; Pga, change in gastric pressure elicited by abdominal stimulation; Tab, cumulative thickness of abdominal muscles; PT, peak torque of quadriceps muscle; quadCSA, cross sectional area of quadriceps muscle. *Mean difference between CF and control groups. 

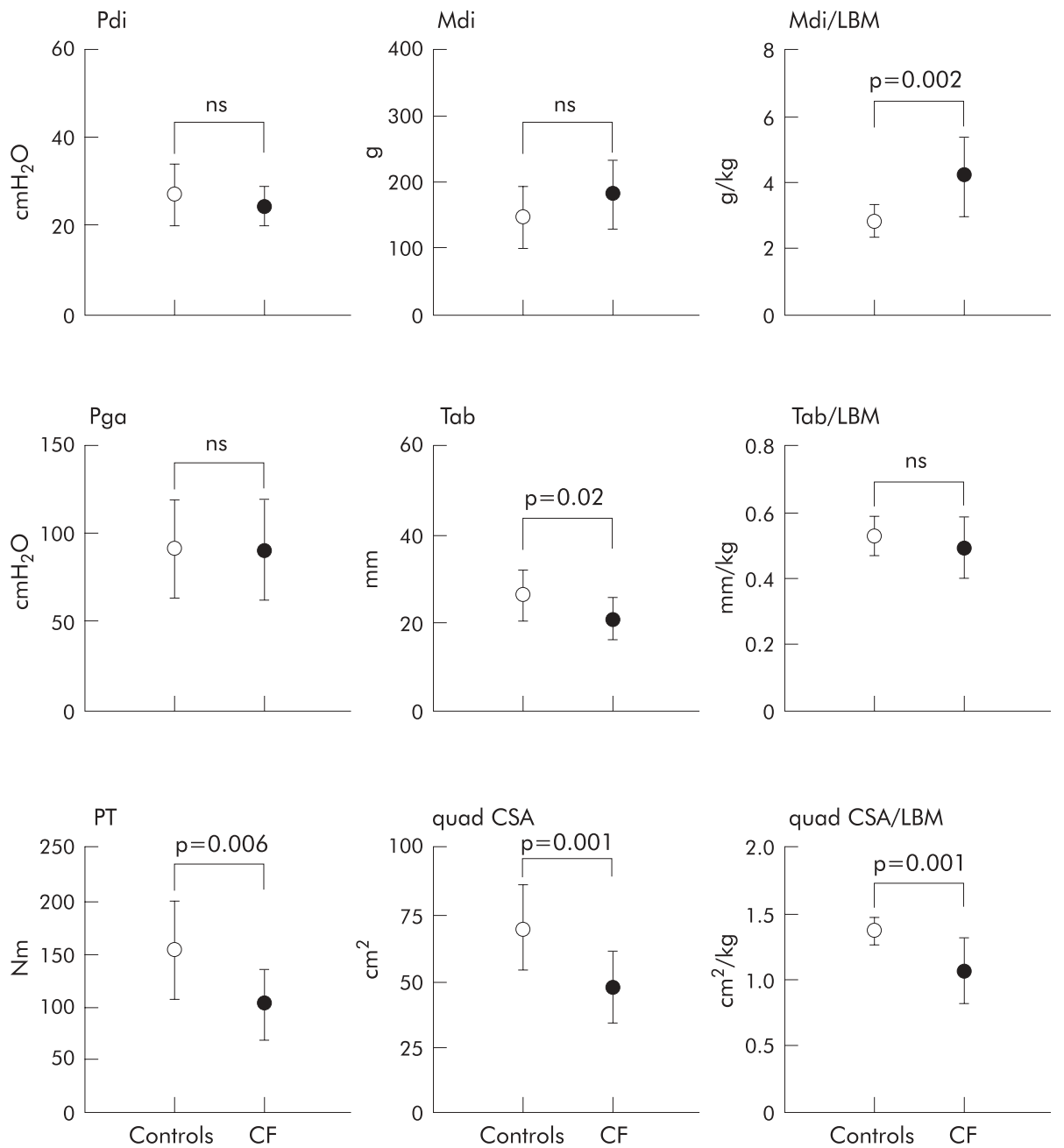

Figure 1 Upper panel: Mean values of transdiaphragmatic pressure (Pdi) elicited by twitch stimulation of the phrenic nerves in 11 CF patients and 12 controls, and of diaphragm mass (Mdi) in 12 CF patients and 12 control subjects. Middle panel: Mean changes in gastric pressure (Pga) elicited by stimulation of the abdominal muscles in 11 CF patients and 12 controls, and mean values of cumulated thickness of the abdominal muscles (Tab) in 12 CF patients and 12 control subjects. Lower panel: Mean values of quadriceps peak torque (PT) and cross sectional area (quad CSA) in 12 CF patients and 12 control subjects. LBM, lean body mass.
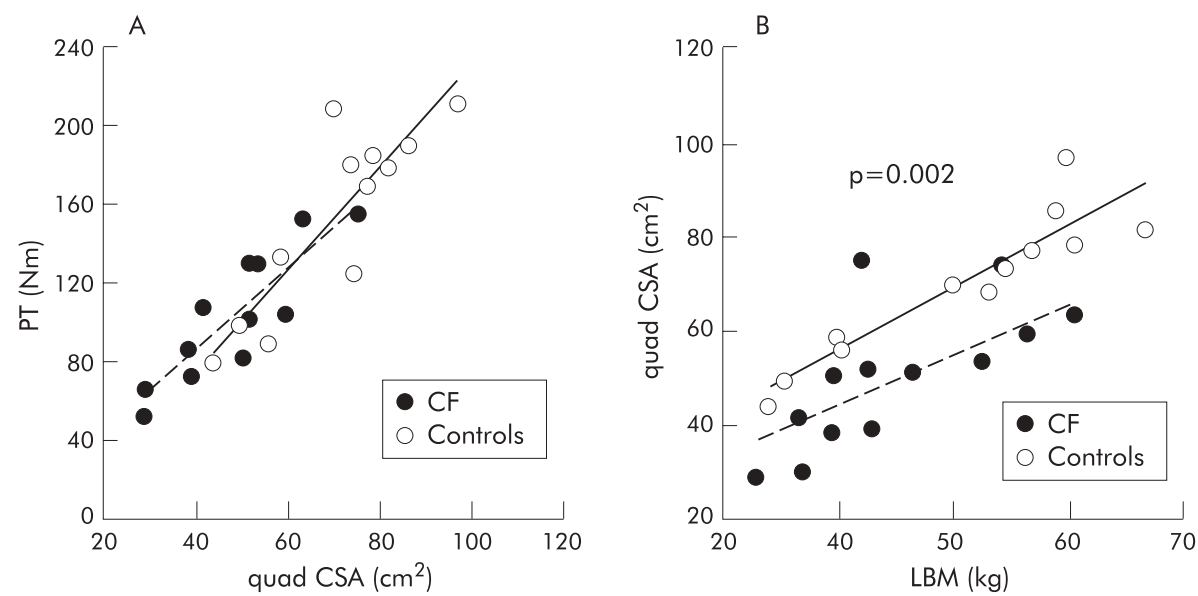

Figure 2 Relationships between (A) quadriceps peak torque (PT) and cross sectional area (quad CSA) and (B) quadriceps cross sectional area (quad CSA) and lean body mass (LBM) in 12 CF patients and 12 control subjects. The $p$ value refers to the significance of the difference in vertical distance between the two regression lines as tested by analysis of covariance. 
A

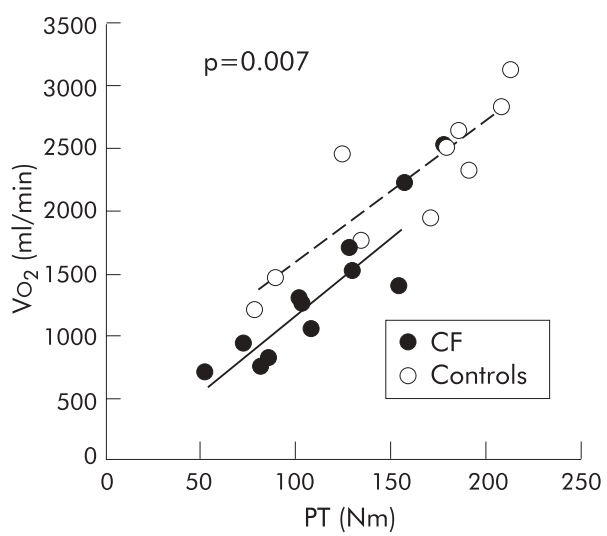

B

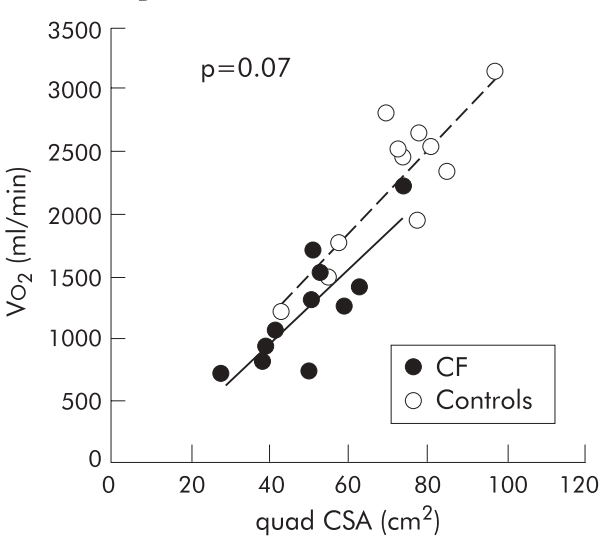

Figure 3 Relationships between peak oxygen uptake $\left(\mathrm{VO}_{2}\right)$ and $(\mathrm{A})$ quadriceps strength (PT) or (B) cross sectional area (quad CSA) in $11 \mathrm{CF}$ patients and 11 control subjects. The $p$ value refers to the significance of the difference in vertical distance between the two regression lines as tested by analysis of covariance.

due to leg pain; two had no symptoms, but it was decided to stop the test because of a high respiratory quotient. For the 11 patients studied, the respiratory quotient at peak exercise averaged 1.31 (1.24-1.37).

Figure 3 shows that peak oxygen uptake was positively correlated with quadriceps strength $\left(r^{2}=0.78\right.$ and 0.77 , $\mathrm{p}<0.001$ in controls and patients, respectively) and cross sectional area $\left(r^{2}=0.73, \mathrm{p}<0.001\right.$ and $r^{2}=0.68, \mathrm{p}=0.002$ in controls and patients, respectively). However, the regression lines computed in the patients were displaced towards lower values of peak oxygen uptake $(p=0.007$ for quadriceps strength; $p=0.07$ for cross sectional area by analysis of covariance). In accord with this, peak oxygen uptake per unit quadriceps strength was lower in patients (11.7 (1.9) $\mathrm{ml} / \mathrm{min} /$ $\mathrm{Nm})$ than in control $(14.5(2.2) \mathrm{ml} / \mathrm{min} / \mathrm{Nm} ; \mathrm{p}=0.005)$. The corresponding values for peak oxygen uptake per unit quadriceps cross sectional area were 24.7 (4.8) $\mathrm{ml} / \mathrm{min} / \mathrm{cm}^{2}$ and $31.0(4.4) \mathrm{ml} / \mathrm{min} / \mathrm{cm}^{2}(\mathrm{p}=0.004)$. Respiratory muscle strength and bulk did not correlate with peak oxygen uptake.

The mean daily dose of methylprednisolone taken by the patients during the year preceding the study amounted to 9.3 (4.3) $\mathrm{mg}$ and the total cumulative dose received between transplantation and study averaged 14.0 (5.6) g. The time elapsed since transplantation, the mean daily dose of methylprednisolone, and the cumulative dose of corticosteroids were not selected by the multiple regression analysis as significant independent predictors of the bulk and strength of diaphragm and abdominal muscles, but they were predictive of quadriceps cross section according to the following equation: quadriceps cross section $=-5.64+1.26^{*} \mathrm{LBM}+$ $0.201^{*}$ time $-0.0010^{*}$ corticosteroids (adjusted $R^{2}=0.83$, $\mathrm{p}=0.002$ ), where LBM is lean body mass, "time" is the time elapsed since surgery, and "corticosteroids" is the cumulative dose of methylprednisolone received since transplantation; replacing the latter by the mean daily dose of methylprednisolone did not improve the prediction. Quadriceps cross section thus tended to increase with postoperative time and to decrease with the total dose of corticosteroids. $43 \%$ of the variance in quadriceps cross section was due to LBM, $27 \%$ was related to the time elapsed since surgery, and the cumulative dose of corticosteroids was responsible for a further $13 \%$. The strength and bulk of the respiratory and quadriceps muscles were similar in patients with HLT and BLT and in patients with and without diabetes mellitus.

\section{DISCUSSION}

This study has shown that, in patients transplanted for CF, the diaphragm and abdominal muscles have preserved strength and bulk but the quadriceps is weak due to muscle atrophy. This atrophy is caused partly by corticosteroid treatment and is closely correlated with the reduction in exercise capacity.

The patients and controls were not matched for weight because one aim of this study was to assess the impact of potential differences in nutritional status on the bulk of respiratory and quadriceps muscles. Body weight, BMI, lean body mass, and fat body mass were all non-significantly reduced in the patients compared with the controls, but analysis of the confidence intervals (table 1) indicates that the differences might have become significant if more patients had been included in the study (type II error). We did not quantify the level of daily physical activity in the two groups. The patients were included in a standard rehabilitation programme during the first 3-4 weeks after transplantation, but no formal revalidation was performed thereafter. At the time of the study two patients and three control subjects were engaged in a sports activity on a regular basis.

Previous studies of respiratory muscle strength in non-CF transplanted subjects have yielded conflicting results, possibly because of differences in patient characteristics in terms of time elapsed since surgery, underlying disease, and pulmonary function, and in the techniques used to assess muscle strength. In addition, interpretation of the data was made difficult by the small number of patients studied and the absence of a control group in most studies. This is the first study to use non-volitional techniques to show that the strength of the diaphragm and abdominal muscles is normal in patients with CF studied about 4 years after transplantation. Consistent with this finding, we found that the bulk of these muscles (normalised by lean body mass) was comparable to, or greater than, that measured in the control subjects. Furthermore, the mean daily dose of methylprednisolone and the cumulative dose of methylprednisolone taken by the patients were not selected by multiple regression analysis as independent predictors of respiratory muscle function and bulk. Together these observations indicate that corticosteroids given after transplantation do not produce significant respiratory muscle weakness or atrophy.

Several studies in non-transplanted CF patients have

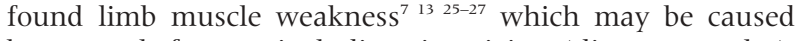
by several factors including inactivity (disuse atrophy), undernutrition, and chronic inflammation. Although these deleterious factors are all expected to improve after transplantation, the present study shows that quadriceps strength remained markedly decreased after the surgical procedure. This is consistent with a previous study which showed that 
leg strength was reduced to $76 \%$ of predicted in nine patients with BLT (of whom seven had CF). ${ }^{5}$ Similarly, Ambrosino and coworkers ${ }^{28}$ found a $35 \%$ decrease in quadriceps strength in 11 non-CF transplant recipients studied 1 year after surgery. In the study by Pantoja and coworkers ${ }^{29}$ the strength of the ankle dorsiflexor muscle measured in nine non-CF patients 17 months after transplantation was decreased by $39 \%$. Based on these reports, leg muscle weakness therefore seems to be a consistent finding after lung transplantation for both CF and other conditions.

Our study provides the novel and important finding that this weakness is primarily related to muscle atrophy (rather than myopathy). As shown in fig $2 \mathrm{~A}$, no patient had a disproportionate decrease in strength compared with muscle mass. Furthermore, the observation that quadriceps cross section per unit lean body mass was significantly decreased in patients compared with controls (fig 2B) indicates that generalised muscle wasting caused by undernutrition could not fully account for quadriceps atrophy-that is, there was a disproportionate loss of quadriceps bulk. Although the mechanisms underlying this alteration are unkonwn, the toxicity of immunosuppressive agents is a likely contributor. Based on previous reports, the mean daily dose of corticosteroids received by our patients seems sufficient to promote muscle wasting, and the multiple regression analysis indicated that the cumulative dose of methylprednisolone was an independent predictor of quadriceps atrophy.

An intriguing finding of this study is that the long term use of corticosteroids did not similarly result in atrophy of the diaphragm and abdominal muscles. Acute myopathy with weakness of respiratory and limb muscles induced by high dose prednisolone has been reported in patients with a variety of diseases including COPD or asthma ${ }^{30}$ and lung transplantation, ${ }^{31}$ but the long term effects of administration of a lower dose of corticosteroids is more controversial. Some, ${ }^{10} 11303233$ but not all, ${ }^{34} 35$ studies in chronic airflow obstruction have shown that weakness of respiratory and/or limb muscles is more likely to occur in patients receiving a low dose of prednisolone. In patients with Cushing's syndrome, Mills and coworkers ${ }^{36}$ found significant weakness of the quadriceps but respiratory muscle strength was close to normal. In fact, the available literature ${ }^{37}$ suggests that the effects of corticosteroids on skeletal muscles may be influenced by a variety of factors including the dose, duration and type of exposure, type of steroids, type of muscle fiber, and underlying disease. Corticosteroids may therefore be more deleterious for muscles that are not continuously active, are proximal, and contain a predominance of type IIb fibres, features which all apply to the quadriceps of lung transplant recipients. $^{38}$ On this basis, it is possible to understand the present finding that corticosteroids produced weakness and wasting of the quadriceps but not of the respiratory muscles.

Seven of the 12 patients in our study had insulin dependent diabetes mellitus which may cause polyneuropathy and muscular atrophy. ${ }^{39}$ Based on the present findings, we cannot precisely determine the extent to which diabetes contributed to quadriceps wasting, but the following observations argue against an important role. Firstly, polyneuropathy is more likely to occur in patients with longstanding and/or ill controlled diabetes. In our patients the median duration of diabetes was 24 months and only one patient had had diabetes for more than 5 years; in addition, the more recent value for glycated haemoglobin at the time of study averaged $7.5 \%$, indicating fairly good control of the disease. Secondly, quadriceps strength and cross section did not differ in patients with and without diabetes. Finally, the presence of diabetes was not selected by the multiple regression analysis as a significant independent predictor of quadriceps atrophy.
Some of the patients were treated with cyclosporin which may also have adverse effects on skeletal muscles. ${ }^{40} \mathrm{~A}$ number of case studies have reported muscular disorders associated with cyclosporin, including myopathy, but it was generally difficult to exclude a causative or potentiating role for other medications such as corticosteroids or statins. In a study in rats, Biring and coworkers ${ }^{41}$ showed that cyclosporin alone had no effect on the proportion and cross sectional area of diaphragm and limb muscle fibres. A direct effect of cyclosporin on the bulk of the quadriceps therefore seems unlikely. To the best of our knowledge, the potential toxicity of tacrolimus on skeletal muscle has not been studied to date.

Our analysis of the relationships between peak oxygen uptake and quadriceps strength or cross sectional area provides some insight into the factors limiting exercise capacity in transplanted CF patients. We observed that the relationships obtained in the patients were displaced towards lower values of peak oxygen uptake (fig 3) -that is, mean values of peak oxygen uptake per unit quadriceps strength or cross sectional area were lower in patients than in controls. These observations indicate that quadriceps atrophy alone could not account for all the impairment in peak oxygen uptake. Several studies in lung transplant recipients have indicated a persistent impairment in exercise capacity, which is present independent of the type of transplant procedure and involves recipients with and without $C F .^{342}$ This impairment has been attributed to a defect originating in the peripheral muscles and limiting oxygen utilisation; this defect may be caused by a generalised deconditioning and by the toxicity of cyclosporin which decreases the oxidative capacity of peripheral muscles by inhibiting mitochondrial respiration and decreasing capillary density. ${ }^{41-46}$ Other possible contributors to the disproportionate decrease in peak oxygen uptake in comparison with quadriceps strength and bulk include a CF related abnormality in muscle oxygen metabolism, ${ }^{6-8}$ increased sensation of fatigue in the peripheral muscles, or impaired oxygen delivery to these muscles, particularly in recipients of heart-lung transplants. ${ }^{47}$

Although the present data do not allow us to assess the relative role played by quadriceps wasting and by derangements in muscle oxygen metabolism, it seems very likely that restoring muscle mass would improve exercise tolerance in transplanted CF patients. Previous studies using aerobic endurance training alone in lung transplant recipients have shown only modest improvements in maximal oxygen uptake after 11 weeks of training (for example, $+11.5 \%$ compared with baseline). ${ }^{48}$ It is likely that adding strategies aimed at increasing muscle bulk such as strength training or anabolic drugs to endurance training alone will produce greater gains in exercise tolerance.

In summary, this cross sectional study has shown that the strength and bulk of the diaphragm and abdominal muscles is preserved in patients who have undergone lung transplantation for CF while the strength of the quadriceps muscle is markedly decreased. Our results also indicate that this reduction is entirely accounted for by muscle atrophy. This atrophy is caused in part by corticosteroid therapy and is closely correlated with the reduction in exercise capacity. Longitudinal studies of limb muscle function, bulk, and histology before and after surgery are now required to acquire a better understanding of the effects of lung transplantation on skeletal muscles and of the mechanisms responsible for quadriceps atrophy.

\section{ACKNOWLEDGEMENTS}

The authors thank B Morlion, R C Sà, and M Paiva (Biomedical Physics Laboratory, ULB, Brussels, Belgium) for their support in the data analysis and G Gayan-Ramirez (Respiratory Muscles Laboratory, KUL, Leuven, Belgium) for helpful discussions on the data. 


\section{Authors' affiliations}

C Pinet, C Knoop, M Estenne, Department of Chest Medicine, Erasme University Hospital, Brussels, Belgium

P Scillia, M Cassart, Department of Radiology, Erasme University Hospital, Brussels, Belgium

M Lamotte, Department of Physiotherapy, Erasme University Hospital, Brussels, Belgium

C Mélot, Department of Intensive Care Medicine, Erasme University Hospital, Brussels, Belgium

$\operatorname{Dr} C$ Pinet was supported by fellowships from the European Respiratory Society (ERS), the Association Régionale d'Assistance Respiratoire à Domicile (ARARD) and the Association pour le Développement des Recherches Biomédicales au Centre Hospitalier de Marseille (ADEREM). The study was supported by the Association Belge de Lutte contre la Mucoviscidose (ABLM).

\section{REFERENCES}

1 Trulock EP, Edwards LB, Taylor DO, et al. The Registry of the International Society for Heart and Lung Transplantation: 20th official adult lung and heart lung transplant report-2003. J Heart Lung Transplant 2003;22:625-35.

2 Egan TM, Detterbeck FC, Mill MR, et al. Long term results of lung transplantation for cystic fibrosis. Eur J Cardiothorac Surg 2002;22:602-9.

3 Oelberg DA, Systrom DM, Markowitz DH, et al. Exercise performance in cystic fibrosis before and after bilateral lung transplantation. J Heart Lung Transplant 1998;17:1104-12.

4 Pinet $\mathrm{C}$, Estenne $\mathrm{M}$. Effect of preoperative hyperinflation on static lung volumes after lung transplantation. Eur Respir J 2000;16:482-5.

5 Lands LC, Smountas AA, Mesiano G, et al. Maximal exercise capacity and peripheral skeletal muscle function following lung transplantation. $J$ Heart Lung Transplant 1999;18:113-20.

6 de Meer K, Jeneson JA, Gulmans VA, et al. Efficiency of oxidative work performance of skeletal muscle in patients with cystic fibrosis. Thorax 1995;50:980-3

7 de Meer K, Gulmans VA, van Der Laag J. Peripheral muscle weakness and exercise capacity in children with cystic fibrosis. Am J Respir Crit Care Med 1999;159:748-54.

8 Moser C, Tirakitsoontorn P, Nussbaum E, et al. Muscle size and cardiorespiratory response to exercise in cystic fibrosis. Am J Respir Crit Care Med 2000; 162:1823-7.

9 Harrington D, Anker S, Chua TP, et al. Skeletal muscle function and its relation to exercise tolerance in chronic heart failure. J Am Coll Cardiol 1997;30:1758-64.

10 Decramer M, Lacquet LM, Fagard R, et al. Corticosteroids contribute to muscle weakness in chronic airflow obstruction. Am J Respir Crit Care Med 1994;150:11-6.

11 Bernard S, LeBlanc $P$, Whittom $F$, et al. Peripheral muscle weakness in patients with chronic obstructive pulmonary disease. Am J Respir Crit Care Med 1998; 158:629-34.

12 Estenne M, Maurer JR, Boehler A, et al. Bronchiolitis obliterans syndrome 2001: an update of the diagnostic criteria. J Heart Lung Transplant 2002;21:297-310

13 Pinet C, Cassart M, Scillia P, et al. Function and bulk of respiratory and limb muscles in patients with cystic fibrosis. Am J Respir Crit Care Med 2003; 168:989-94.

14 American Thoracic Society. Standardization of spirometry: 1994 update. Am Rev Respir Dis 1995;152:1107-36.

15 Quanjer P, Tammeling GJ, Cotes JE, et al. Lung volumes and forced ventilatory flows : report of the working party standardization of lung function tests. European Coal and Steel Community. Eur Respir J 1993;6(Suppl 16):5-40.

16 Hansen JE, Sue DY, Wasserman K. Predicted values for clinical exercise testing. Am Rev Respir Dis 1984;129(Suppl):S49-55.

17 Pettiaux N, Cassart M, Paiva $M$, et al. Three-dimensional reconstruction of human diaphragm with the use of spiral computed tomography. J Appl Physiol 1997;82:998-1002

18 Cassart M, Pettiaux N, Gevenois PA, et al. Effect of chronic hyperinflation on diaphragm length and surface area. Am J Respir Crit Care Med 1997: 156:504-8.

19 Ueki J, De Bruin PF, Pride NB. In vivo assessment of diaphragm contraction by ultrasound in normal subjects. Thorax 1995;50:1157-61.
20 Bellemare F, Bigland-Ritchie B. Assessment of human diaphragm strength and activation using phrenic nerve stimulation. Respir Physiol 1984;58:263-7.

21 Similowski T, Yan S, Gauthier AP, et al. Contractile properties of the human diaphragm during chronic hyperinflation. N Engl J Med 1991;325:917-23.

22 Estenne M, Pinet C, De Troyer A. Abdominal muscle strength in patients with tetraplegia. Am J Respir Crit Care Med 2000;161:707-12.

23 Jeeieebhoy KN. Nutritional assessment. Nutrition 2000;16:585-90.

24 Arora NS, Rochester DF. Effect of body weight and muscularity on human diaphragm muscle mass, thickness, and area. J Appl Physiol 1982;52:64-70.

25 Hussey J, Gormley J, Leen G, et al. Peripheral muscle strength in young males with cystic fibrosis. J Cystic Fibrosis 2002;1:116-21.

26 Elkin SL, Williams L, Moore M, et al. Relationship of skeletal muscle mass, muscle strength and bone mineral density in adults with cystic fibrosis. Clin Sci (Lond) 2000;99:309-14.

27 Lands LC, Heigenhauser GJ, Jones NL. Respiratory and peripheral muscle function in cystic fibrosis. Am Rev Respir Dis 1993;147:865-9.

28 Ambrosino N, Bruschi C, Callegari G, et al. Time course of exercise capacity, skeletal and respiratory muscle performance after heart-lung transplantation. Eur Respir J 1996;9:1508-14.

29 Pantoja JG, Andrade FH, Stoki DS, et al. Respiratory and limb muscle function in lung allograft recipients. Am J Respir Crit Care Med 1999;160:1205-11.

30 Decramer M, Stas KJ. Corticosteroid-induced myopathy involving respiratory muscles in patients with chronic obstructive pulmonary disease or asthma. Am Rev Respir Dis 1992; 146:800-2.

31 Nava S, Fracchia C, Callegari G, et al. Weakness of respiratory and skeletal muscles after a short course of steroids in patients with acute lung rejection. Eur Respir J 2002;20:497-9.

32 Decramer M, de Bock V, Dom R. Functional and histologic picture of steroidinduced myopathy in chronic obstructive pulmonary disease. Am J Respir Crit Care Med 1996; 153:1958-64.

33 Barry SC, Gallagher CG. Corticosteroids and skeletal muscle function in cystic fibrosis. J Appl Physiol 2003;95:1379-84.

34 Bowyer SL, LaMothe MP, Hollister JR. Steroid myopathy: incidence and detection in a population with asthma. J Allergy Clin Immunol 1985;76:234-42

35 Picado C, Fiz JA, Montserrat JM, et al. Respiratory and skeletal muscle function in steroid-dependent bronchial asthma. Am Rev Respir Dis 1990;141:14-20.

36 Mills GH, Kyroussis D, Jenkins $P$, et al. Respiratory muscle strength in Cushing's syndrome. Am J Respir Crit Care Med 1999:160:1762-5.

37 Gayan-Ramirez G, Decramer M. Corticosteroids and muscle function in stable COPD. In: Lenfant C, eds. Clinical management of stable COPD. New York: Marcel Dekker, 2002:639-58.

38 Wang XN, Williams TJ, McKenna MJ, et al. Skeletal muscle oxidative capacity, fiber type, and metabolites after lung transplantation. Am J Respir Crit Care Med 1999;160:57-63.

39 Andersen H, Gadeberg PC, Brock B, et al. Muscular atrophy in diabetic neuropathy: a stereological magnetic resonance imaging study. Diabetologia 1997:40:1062-9.

40 Breil M, Chariot P. Muscle disorders associated with ciclosporine treatment. Review. Muscle Nerve 1999;22:1631-6.

41 Biring MS, Fournier M, Ross DJ, et al. Cellular adaptations of skeletal muscles to cyclosporine. J Appl Physiol 1998:84:1967-75.

42 Krieger AC, Szidon P, Kesten S. Skeletal muscle dysfunction in lung transplantation. J Heart Lung Transplant 2000;19:392-400.

43 Hokanson JF, Mercier JG, Brooks GA. Cyclosporine A decreases rat skeletal muscle mitochondrial respiration in vitro. Am J Respir Crit Care Med 1995:151:1848-51.

44 Mercier JG, Hokanson JF, Brooks GA. Effects of cyclosporine A on skeletal muscle mitochondrial respiration and endurance time in rats. Am J Respir Crit Care Med 1995;151:1532-6.

45 Evans AB, Al-Himyary AJ, Hrovat Ml, et al. Abnormal skeletal muscle oxidative capacity after lung transplantation by ${ }^{31} \mathrm{P}-\mathrm{MRS}$. Am J Respir Crit Care Med 1997; 155:615-21.

46 Tirdel GB, Girgis R, Fishman RS, et al. Metabolic myopathy as a cause of the exercise limitation in lung transplant recipients. J Heart Lung Transplant 1998;17:1231-7.

47 Vachiery JL, Niset G, Antoine M, et al. Haemodynamic response to dynamic exercise after heart-lung transplantation. Eur Respir J 1999;14:1131-5.

48 Stiebellehner L, Quittan M, End A, et al. Aerobic endurance training program improves exercise performance in lung transplant recipients. Chest $1998 ; 113: 906-12$. 